\title{
WUJUD KESANTUNAN ASERTIF DAN IMPERATIF DALAM BAHASA BANJAR
}

The Form of Assertive and Imperative Politeness in Banjar Language

Rissari Yayuk, M.Pd.

Balai Bahasa Kalimantan Selatan

\begin{abstract}
Abstrak
Kesantunan berbahasa oleh generasi sekarang mengalami pergeseran akibat berbagai faktor. Penting dilakukan pelestarian wujud kesantunan berbahasa yang bsa dijadikan contoh ajar bagi peningkatan kecerdasan berbahasa anak-anak sekarang maupun akan datang dalam ragam tindak tutur. Masalah yang dikaji meliputi 1) Bagaimana Wujud kesantunan tindak tutur asertif dalam bahasa Banjar, 2) Bagaimana wujud Tindak Tutur imperatif dalam bahasa Banjar. Tujuan yang ingin dicapai adalah mendeskripsikan, 1) Wujud kesantunan tindak tutur asertif dalam bahasa Banjar, 2) wujud Tindak Tutur imperative dalam bahasa Banjar. Metode penelitian ini adalah deskriptif Teknik yang digunakan dalam pengambilan data adalah teknik rekam dan dokumentasi. Sumber data diambil dari wilayah yang dianggap mewakili masyarakat Banjar saja, yaitu Kabupaten Banjar. Waktu pengambilan data selama 2 bulan , dari Awal Januari 2016 s.d. 30 Akhir Februari 2016. Hasil penelitian menunjukkan Wujud kesantunan berbahasa yang terdapat dalam tindak tutur asertif dapat dilihat dalam wujud basa-basi dan kata sapaan. Wujud kesantunan berbahasa yang terdapat dalam tindak tutur imperative dapat dilihat dalam wujud basa-basi dan kata sapaan.
\end{abstract}

Kata Kunci: kesantunan, asertif, imperatif.

\begin{abstract}
Politeness by the present generation has shifted as a result of various factors. Important to the preservation of a form of politeness that coud be used as a teaching example for increased intelligence-speaking children today and will come in a variety of speech acts. The problem studied include 1) How Being assertive speech act of politeness Banjar, 2) How to form the Speech Acts imperative Banjar. The aim is to describe, 1) Being assertive speech act of politeness Banjar, 2) form the Speech Acts imperative Banjar. This research method is descriptive technique used in data collection and documentation is a recording technique. Sources of data taken from the area which is considered to represent the people of Banjar, namely Banjar. Time data capture for 2 months, from the beginning of January 2016 s.d. End of February 30, 2016. The results showed Being politeness contained in an assertive speech act can be seen in the form of pleasantries and politeness sapaan. Wujud words contained in the imperative speech acts can be seen in the form of pleasantries and greeting words.
\end{abstract}

Keywords: politeness, assertive, imperative.

\section{PENDAHULUAN}

Bahasa alat menyampaikan pikiran (Masinambouw dalam Chaer, dkk, 2011:167). Koetjaraningrat (dalam Chaer, dkk, 2011: 165) menyatakan salah satu untur kebudayaan adalah bahasa. Nababan dalam (Chaer, dkk, 2011:163-4) menyatakan bahasa adalah 
bagian dari budaya yang memiliki fungsi sebagai sistem komunikasi untuk menjalin kerjasama, kesantunan dan kelangsungan hidup masyarakat .

Kecerdasan berhubungan dengan kepintaran atau ketajaman berpikir, bijaksana dalam bersikap, dan berdayanya kepekaan hati, sehingga menghasilkan tindakan yang elok. Berdasarkan pendapat ini, kecerdasan mengandung hal-hal yang berkaitan dengan otak atau intelektual yang tajam, hati yang bijak dan tindakan yang elok dan tangkas. Hal ini berarti pula, Kecerdasan seseorang secara umum tidak hanya dilihat dari segi prestasi yang berwujud angka atau jabatan. Namun kecerdasan seseorang dapat pula dilihat dari tindak berbahasa yang dia lakukan kala dia menyampaikan pikiran dengan tujuan menjalin kerjasama atau berinteraksi dengan masyarakat sekitar dalam kehidupan sehariharinya. Tindak berbahasa tersebut hasil dari ketajaman akal dan kepekaan hatinya dalam memahami lingkungan sehingga mampu menghasilkan sikap yang beretika atau elok. Dengan kata lain seseorang dikatakan cerdas, antara lain ditentukan oleh santun berbahasa yang dia miliki saat bertutur kata, sebab kala berbahasa seseorang membutuhkan pemikiran, perasaan dan tindakan yang selaras dengan norma sosial budaya yang berlaku.

Bahasa memang menunjukkan bangsa.manusia yang cerdas adalah manusia yang berbudaya. Hal ini sesuai pula dengan apa yang dinyatakan Chaer, dkk.( 2011:172) yaitu, santun berbahasa erat kaitannya dengan pemilihan kode bahasa, norma sosial, dan sistem budaya yang berlaku dalam masyarakat. Pendapat Chaer ini menggambarkan bahwa hanya orang yang cerdas akal, berpengetahuan luas, dan peka hati akan hal-hal yang berhubungan dengan konteks di sekitarnya saja yang bisa bertindak tutur santun atau beretika. Dengan demikian santun berbahasa ini sangat berperan penting kala anggota tutur saling berkomunikasi untuk mencapai tujuan tertentu.

Santun berbahasa ini tidak begitu saja diperolehnya kala dia dewasa melalui dunia pendidikan formal. Dunia pendidikan dilingkungan keluarga yang membesarkannya sejak kecil adalah salah satu ranah penentu bagi pertumbuhan dan perkembangan santun berbahasa yang dimilikinya. Bagi masyarakat daerah, pendidikan santun berbahasa di dalam keluarga ini dilakukan antara lain melalui tindak tutur keseharian yang diujarkan oleh orang tua kepada generasi berikutnya.

Santun berbahasa di era sekarang mengalami pergeseran akibat pengaruh globalisasi yang tidak bisa dihindarkan. Oleh karena itu, banyak peristiwa sepele 
mengakibatkan terjadinya perselisihan akibat kurangnya kesantunan berbahasa. Brown dan Levinson (1987) (dalam Rahardi, 2005:67) menyatakan, santun berbahasa memang sangatlah penting diperhatikan dalam kehidupan sosial untuk menghindari konflik yang mungkin terjadi dalam setiap interaksi komunikasi.

Berdasarkan paparan di atas, penting kiranya pelestarian budaya berbahasa yang mengandung nilai santun bagi anak-anak kita atau generasi penerus bangsa. Nilainilai santun dalam berbahasa, khususnya bahasa daerah atau bahasa ibu, dapat diajarkan melalui tindak tutur santun berbahasa secara langsung atau tidak dari keluarga masingmasing dan lingkungan sekitar pada umumnya.

Tindak tutur yang dimaksudkan di sini sesuai dengan apa yang dimaksudkan Yule (dalam Jumadi, 2005: 82), ia menyatakan bahwa "Tindak tutur merupakan tindakantindakan yang ditampilkan lewat tuturan, misalnya usaha seseorang dalam mengungkapkan diri mereka. Mereka tidak hanya menghasilkan tuturan yang mengandung kata-kata saja, tetapi mereka memperlihatkan tindakan-tindakan melalui tuturan itu”. Maksudnya sudah jelas bahwa jika seseorang ingin mengungkapkan sesuatu maka ia akan menunjukkannya melalui tindakan yang disampaikan dengan ujaran.

Penelitian ini adalah salah satu upaya untuk mendokumentasikan dan memberikan informasi tentang adanya ajaran budaya santun berbahasa pada tindak tutur masyarakat daerah, khususnya yang terdapat pada penutur bahasa Banjar dari generasi ke generasi. Masalah yang dikaji meliputi: 1) Bagaimana Wujud kesantunan tindak tutur asertif dalam bahasa Banjar; dan 2) Bagaimana wujud Tindak Tutur imperatif dalam bahasa Banjar

\section{KERANGKA TEORI}

Kramsch (dalam Rahadi, 2005) berpendapat bahasa santun akan berfungsi dalam dua cara, semuanya berhubungan dengan budaya: (1) Melalui apa yang dikatakan dan apa rujukannya atau yang disebut semantik, dan (2) Melalui apa yang dilakukan dalam konteks atau dikenal dengan istilah pragmatik.

Geertz, (1960) dalam Yayuk (2012:173) menyatakan bahwa sistem penggunaan bahasa yang mendasari kesantunan berbahasa dapat disebut "sopan-santun berbahasa" atau honorifics ini lazim diungkapkan dengan kata ganti orang, sistem sapaan, penggunaan gelar dan sebagainya. Dalam beberapa bahasa, perbedaan tingkat sosial 
antara pembicara dengan si alamat/pendengar diwujudkan dalam seleksi kata dan/atau sistem morfologi kata-kata tertentu.

Leech (1983) (dalam Yayuk , 2012:173) menyatakan beberapa aturan atau maksim dalam prinsip kesantunan, yaitu (1) maksim kebijakan yang mengutamakan kearifan bahasa, (2) maksim penerimaan yang mengutamakan keuntungan untuk orang lain dan kerugian untuk diri sendiri, (3) maksim kemurahan yang mengutamakan kesalutan/rasa hormat pada orang lain dan rasa kurang hormat pada diri sendiri, (4) maksim kerendahan hati yang mengutamakan pujian pada orang lain dan rasa rendah hati pada diri sendiri, (5) maksim kecocokan yang mengutamakan kecocokan pada orang lain, dan (6) maksim kesimpatisan yang mengutamakan rasa simpati pada orang lain. Dengan menerapkan prinsip kesopanan ini, orang tidak lagi menggunakan ungkapan-ungkapan yang merendahkan orang lain sehingga komunikasi akan berjalan dalam situasi yang kondusif.

Searle (1983) dalam Ibrahim (1995:27) menyebutkan ada lima bentuk tindak tutur yang dilakukan orang sewaktu memproduksi ujaran dilihat dari fungsi ilokusinya. Pembagian Searle didasarkan bentuk tuturan dan kategori tindakan yang dilakukan oleh seseorang. Dua diantaranya adalah sebagai berikut

1. Tindak tutur asertif atau biasa juga disebut tindak tutur representatif adalah tindak tutur yang berkaitan dengan menyatakan sesuatu. Tindak tutur ini mengikat penuturnya akan kebenaran atas apa yang diujarkan. Bentuk tindak tutur ini biasanya dilakukan orang sewaktu dia mengemukakan pendapat/ menyatakan sesuatu, berspekulasi, mengklaim, dan melaporkan. Biasanya penanda tindak tutur asertif antara lain modalitas mungkin, barangkali, tepat sekali, betul dan lain-lain.

2. Tindak tutur imperatif adalah tidak tutur yang dimaksudkan agar lawan bicara melakukan sesuatu, fungsinya seperti meminta, menyarankan, melarang, serta memerintah. Biasanya penanda tindak tutur direktif adalah modalitas seperti mohon, ayo, hendak, tolong, harap,mari, harap.

\section{METODE PENELITIAN}

Metode penelitian ini adalah deskriptif. Metode ini menggambarkan fenomena yang terjadi pada tuturan yang ada secara empiris. Hal ini sesuai dengan pendapat 
Djajasudarma (1993:54) dan Moleong (1995:68) yang mengatakan bahwa data yang digunakan bersifat akurat dan alamiah. Data yang dihasilkan berupa deskripsi penggunaaan bahasa penuturnya. Teknik yang digunakan dalam pengambilan data adalah teknik rekam dan dokumentasi.

Sumber data diambil dari wilayah yang dianggap mewakili masyarakat Banjar saja, yaitu Kabupaten Banjar. Waktu pengambilan data selama 2 bulan, dari Awal Januari 2016 s.d. 30 Akhir Februari 2016.

\section{PEMBAHASAN}

\section{Wujud kesantunan tindak tutur asertif dalam bahasa Banjar}

a. Wujud Basa-Basi

Data 1

A: Kayanya hari ini cagar lakas karing pulang tatapasan.

'Sepertinya hari ini bakal cepat kering lagi cucian'

B: Iya pinanya kaya itu pang, embah, sumalam aku batatapas kamarian, ku jamur di banturan, sakalinya pas baisukan karing hudah. Tuntung garhana nih arinya pina humam banar

'Iya sepertinya seperti itu, coba, kemarin aku mencuci sore, ku jemur di beranda, ternyata pas paginya kering sudah. Selesai gerhana ini hari sepertinya gerah sekali'

Konteks:

Tuturan antar tetangga

Data satu adalah tuturan yang memiliki tema tentang udara yang sangat panas sehingga jemuran cepat kering. Tuturan terjadi antar tetangga saat berbasa -basi. Mitra tutur (a) kebetulan sedang duduk-duduk di depan rumah lalu penutur (b) keluar dari rumahnya sambil membawa cuciaan untuk dijemur. Mitra tutur melakukan percakapan dan ditanggapi penutur agar terjalin komunikasi yang lancar, salah satu tujuan basa-basi ini adalah menjaga hubungan yang baik antar warga atau anggota masyarakat Banjar.

Saat itu mitra tutur sedang berpendapat atau berspekulasi kalau jemuran milik tetangganya tersebut akan cepat kering. Berikutnya, penutur menyatakan perkiraan kebenaran atas apa yang dikatakan lawan tutur. Penutur menggunakan prinsip kesantunan atau maksim kecocokan. Penutur menanggapi ujaran lawan tutur dengan menyatakan hal senada, bahkan dia menceritakan bagaimana cuciannya cepat kering meski dijemur saat menjelang malam dan diletakan di teras rumah. Dia juga merasakan udara yang teramat sangat setelah terjadi gerhana matahari total beberapa waktu yang lalu. 
Penanda prinsip kesantunan pada tuturan penutur sebagaimana yang dimaksudkan Searle (1983) dalam Ibrahim (1993:27) adalah iya pinanya kaya itu pang'iya sepertinya begitu'. Penutur berupaya mendukung pendapat mitra tutur. Meskipun sebenarnya jika di mau, penutur bisa saja tidak memberi tanggapan ( diam). Atau bisa juga dia mematahkan pendapat dengan mengatakan 'ah tidak mesti juga, kan hujan bisa saja turun tiba-tiba'. Namun hal ini tidak dilakukannya. Sebab jika hal itu terjadi, kemungkinan komunikasi akan terhenti seketika, sementara mitra tutur juga akan kecewa sebab spekulasinya telah dipatahkan.

b. Wujud Sapaan

Data [2]

\section{A: Ma kanapa datang lambat?}

'Bu kenapa datang terlambat?'

B: Eh Uma tadi liwat di muka sakulahan piyan, sakalinya Uma malihat ada tabrakan, iya tagana, makanya talambat.

'Eh Ibu tadi lewat depan sekolahmu, ternyata Ibu melihat ada tabrakan, maka terheni di sana, jadi terlambat'.

Konteks:

Pecakapan antara orang tua dengan anak

Data [2] terjadi antar ibu dengan anak dalam sebuah rumah. Saat itu sianak atau mitra tutur bertanya mengapa sang ibu atau penutur terlambat. Penutur mengatakan bahwa dia terlambat akibat melihat peristiwa tabrakan di depan jalan sekolah anaknya tersebut.

Pada data [2] penutur menggunakan prinsip kesantunan maksim kemurahan yang mengutamakan kesalutan/rasa hormat pada orang lain dan rasa kurang hormat pada diri sendiri. Penutur menggunakan penanda sapaan kata ganti piyan'anda' kepada ananknya. Penggunaan sapaan ini biasanya digunakan untuk orang yang dihormati atau untuk orang yang usianya lebih tua dari penutur. Namun saat itu penutur karena kasih sayang, dia menggunakan sapaan honorofik kepada anaknya tersebut. Ditambah lagi penutur menggunakaan sapaan diri dengan menggunakan kata Uma'ibu'. Istilah budaya orang Banjar, penggunaan kata ini ini adalah 'Kada basisi”. Artinya tidak menggunakan kata ganti orang (aku, ikam) secara langsung untuk orang yang kita hormati, sayangi, atau yang lebih tua dari kita. 
Penutur tidak melakukan pelanggaran kesantunan berbahasa disebabkan dia menggunakan kata sapaan untuk anak atau mitra tutur dan untuk dirinya sebagai penutur dengan sapaan yang mengandung penghormatan. Padahal jika dia ingin melanggar prinsip ini, mitra tutur bisa menggunakan kata ikam untuk menyapa anaknya dan aku untuk memanggilkan dirinya sendiri.

Data [2] inilah contoh kesantunan yang penting dilestarikan hingga sekarang.Dalam kenyataannya, dilapangan ternyata sudah banyak sudah anak-anak yang kurang menghargai norma kesantunan ini, Hal ini terjadi di era modern sekarang. Anakanak ada saja yang menyapa dirinya dengan sebutan aku atau unda ketika berbicara dengan orang tua. Orang tua juga banyak yang menggunakan kata aku untuk menyebutkan kata ganti dirinya, dan mengatakan ikam untuk menyebutkan kata ganti anaknya.

\section{Wujud Tindak Tutur imperative dalam bahasa Banjar}

a. Wujud Basa-Basi

Data [3]

A: Naik nyiur nah

'Naik kelapa nah'

B: Umai tingginya, hati-hatilah kalu gugur

'Aduh tinggi, hati-hati ya kalau-kalau jatuh'

Konteks:

Dituturkan antar tetangga

Data [3] terjadi di tepi jalan, depan rumah warga. Saat itu mitra tutur sedang menaiki pohon kelapa. Melihat ada yang lewat di bawah pohon tersebut, mitra tutur menegur penutur. Mitra tutur menyatakan bahwa dia sedang naik pohon kelapa. Mendengat mitra tutur berkata tentang apa yang dilakukannya. Penutur pun berbasa-basi dengan mengatakan agar mitra tutur hati-hati saat naik pohon kelapa tersebut, sebab pohonnya tinggi sekali.

Penutur menggunakan maksim kesimpatisan yang mengutamakan rasa simpati pada orang lain.Penutur berbasa-basi namun dalam basa-basinya dia menitip pesan agar mitra tutur berhati-hati supaya jangan jatuh. Penutur sebenarnya sudah tahu kalau mitra tutur tukang naik kelapa yang lihai, namun demi menjalin keakraban dengan mitra tutur, penutur melakukan tindak imperatif yang memegang prinsip kesantunan kesimpatisan. 
Padahal jika saja penutur tidak memagang prinsip ini, kemungkinan dia hanya diam saja tanpa memberi tanggapan apa-apa atas pernyataan mitra tutur. Namun saat itu penutur memerintahkan secara halus atau menyarankan agar mitra tutur berhati-hati. Penutur berharap tanggapannya akan tetap membuat jalinan keakraban antar warga tetap terus terjaga, sebab melalui tanggapannya dalam basa-basi tersebut, secara tidak langsung mitra tutur merasa diperhatikan penutur.

\section{b. Wujud Sapaan}

Data [4]

A: Umai banyaknya lah kambang nang ditukar

'Aduh banyak ya kembang yang dibeli?'

B: Inggih nah, kawakah ulun minta tolong Ka, bawaakan sabuting dua buting nah

konteks:

Tuturan antar dua saudara

Data [4] dituturkan oleh seorang adik kepada kakaknya. Saat itu penutur sedang membongkar beberapa kantong berisi kembang yang baru dibelinya untuk tamannya. Secara kebetulan mitra tutur datang mendekat dan memberi komentar tentang jumlah kembang yang baru dibelinya. Mendengar komentar dan melihat kedatangan mitra tutur, penutur spontan melakukan tindak imperative permintaan. Penutur meminta mitra tutur agar berkenan membawakan beberapa kantong bunganya ke taman belakang rumah mereka.

Penutur menggunakan imperatif permintaan dengan penanda kawakah'bisakah'. Penutur menggunakan maksim kerendahatian kepada mitra tutur. Meskipun kembang tersebut digunakan untuk memperindah taman bersama, namun penutur melakukan permintaan santun kepada kakanya dengan menggunakan kalimat perintah tidak langsung.

Padahal jika penutur tidak memegang prinsip kerendahatian, dia bisa langsung menyuruh kakaknya untuk membawakan bukusan kembang-kembang tersebut. Namun penutur memperhalus permintaannnya kepada mitra tutur tersebut. Penutur menyebut mitra tutr dengan sebutan kaka atau ka. Di sini tidak ada menggunakan budaya berbahasa basisi'sebut langsung'. Penutur tidak menggunakan nama panggilan saudaranya tersebut, 
dia menggunakan kata sapaan kakak'ka' sebagai wujud penghomatan dirinya kepada saudar tuanya tersebut.

c. Tabu atau Pamali

Data (5)

A: Ma ulun turunlah

'Cil saya keluar ya'

B: Mun kawa kaina haja hulu, pamali anak bini-bini kaluar pas magrib kaina bisa kana ampun urang

'Kalu bisa nanti dulu, pamali anak perempuan keluar kala magrib

Konteks: nanti bisa terkena punya orang'

Dituturkan oleh seorang ibu kepada teman anaknya

Data [5] terjadi dalam sebuah rumah antara seorang ibu dengan teman anak perempuannya. Kala itu azan baru saja berkumandang. Teman anak perempuannya (mitra tutur) bergegas akan pulang. Setelah minta izin kepada penutur, ternyata penutur menangapi ujaran mitra tutur dengan menggunakan kalimat tabu atau larangan dalam bahasa Banjar.

Penutur mengatakan mun kawa kaina haja hulu, pamali anak bini-bini kaluar pas magrib kaina bisa kana ampun urang 'Kalu bisa nanti dulu, pamali anak perempuan keluar kala magrib nanti bisa terkena punya orang'. Pernyataan ini sebagai wujud tindak tutur berbahasa imperatif larangan dengan menggunakan prinsip kesantunan kesimpatisan, maksim kesimpatisan ini mengutamakan rasa simpati pada orang lain. Penutur mencoba melarang mitra tutur untuk tidak keluar rumah saat magrib tiba.

Ujaran yang terdapat pada data [5] merupakan kalimat pamali atau tabu. Bagi sebagian masyarakat Banjar, anak perempuan keluar rumah kala magrib adalah sebuah tabu. Mereka beranggapan saat itu akan mendatangkan marabahaya bagi perempuan yang berada di luar rumah.

\section{SIMPULAN}

Wujud kesantunan berbahasa yang terdapat dalam tindak tutur asertif dapat dilihat dalam wujud basa-basi dan kata sapaan. Tindak tutur imperative dapat dilihat dalam wujud basa-basi dan kata sapaan juga pamali. Kesantunan yang dilakukan oleh orang tua dan anggota masyarakat lainnya dalam kehidupan masyarakat Banjar dapat dijadikan 
cermin kecerdasan bagi generasi berikutnya atau anak-anak kita. Dari apa yang kita contohkan dalam berbasa-basi dan saling menyapa , juga mendengar kalimat larangan atau pamali dalam kehidupan sebagai mahluk sosial, adalah bagian budaya berbahasa yang penting dijaga keberadaannya.

\section{DAFTAR PUSTAKA}

Chaer, Abdul dkk. (2011). Sosiolinguistik. Jakarta: Rineka

Djjasudarma, T. Fatimah. (1993). Metode Linguistik; Ancangan Metode Penelitian dan Kajian. Bandung. PT Eresco

Ibrahim, Abdul Syukur. (1995). Kajian Tindak Tutur. Surabaya: Usaha Nasional Jumadi. (2005). Representasi Kekuasaan. Jakarta. Pusat Bahasa.

Moleong, L. J. (1995). Metodologi Penelitian Kualitatif. Bandung: Remaja Rosdakarya. Rahardi R. Kunjana. (2005). Pragmatik. Jakarta:Erlangga

Yayuk, Rissari. (2013). Pelanggaran Prinsip Kesantunan Supir Angkutan Umum Jurusan Martapura. Prosiding Seminar Kebahasaan dan Kesastraan Yokyakarta .Yoyakarta: Balai Bahasa Yogyakarta

Yule, George. (1996). Pragmatics. Terjemahan Jumadi. 2006. Pragmatik. Banjarmasin: Unlam. 